\title{
COMPARISON BETWEEN ELISA AND VARIOUS STAINS TECHNIQUES IN LABORATORY DIAGNOSIS OF CRYPTOSPORIDIOSIS
}

\section{By}

NABIL S. GABR, MANAL Z. M. ABDELLATIF, EKHLAS H. ABD EL-HAFEEZ*
AND REHAM A. M. ABD RABOU

Department of Parasitology, Faculty of Medicine, Minia University, Minia, 61519, Egypt (*Correspondence e-mails: ekhlasha@yahoo.com \& manalzma@yahoo.com.

Abstract

Cryptosporidium spp. is an important parasitic protozoa causing diarrhea which is a severe life-threatening diarrhea especially in immunocompromised hosts. We aimed to evaluate the usefulness of detection of Cryptosporidium spp. copro-antigen from fecal specimens by using enzyme linked immunosorbent assay (ELISA) test and comparing its sensitivity and specificity with some staining methods. The results revealed that Modified Acid-Fast stain is considered better than Giemsa in detecting Cryptosporidium species oocysts in faecal smears as their sensitivity were $67.5 \%$ and $53.75 \%$ respectively. On contrary, ELISA technique is considered the best method used for detection of cryptosporidial infection as its sensitivity is $90 \%$.

Key words: Egypt, Cryptosporidium parvum, persistent diarrhea and ELISA technique

\section{Introduction}

Cryptosporidiosis is one of the infectious zoonotic protozoan diseases. Several species belonging to the genus Cryptosporidium are recorded in human and many vertebrates (Xiao et al, 2004). The first case of human cryptosporidiosis was reported in 1976 in a 3.5-year-old girl from rural Tennessee who developed self-limited gastroenteritis (Nime et al, 1976). Cryptosporidiosis is a worldwide infection with prevalence rates being higher in developing (5 to $10 \%$ ) than in developed (1to 3\%) countries (Current and Garcia, 1991). At the end of the twentieth century, Cryptosporidium species emerged as an important etiologic agent of diarrheal disease worldwide (Fayer et al, 2000).

Cryptosporidium species are protozoan parasites that cause infection and diarrheal illness in a wide range of mammalian species (Priest et al, 2006). The disease can affect both immunocompetent and immunocompromised individuals causing a wide spectrum of diseases ranging from asymptomatic carrier state to severe diarrhea. Infection with this parasite results in severe but selflimiting diarrhea in immunocompetent and often lethal diarrhea in the immunocompromised individuals (Chen et al, 2002).
Man and mammaks can be infected with Cryptosporidium parvum. Outbreaks have been described as a result of transmission in day care centers, swimming pools, public water supplies, and other water sources (Current and Garcia, 1991). Several methods for identification of cryptosporidial oocysts in fecal specimens include microscopy and ELISA, which detect cryptosporidial antigen in stool (Huang et al, 2004). Because of the difficult and time-consuming nature of conventional microscopic examination for the detection of Cryptosporidium oocysts, there is a need for a simple, rapid, and objective test for the copro-diagnosis of Cryptosporidium infection. This need is further underscored by a recent paper suggesting that all of the currently available microscopic methods have a low sensitivity for the detection of oocysts (Weber et al, 1991). The existence of a reliable and relatively inexpensive stool ELISA would obviate the current need for the intensive training and/or expensive equipment necessary to accurately diagnose Cryptosporidium infection.

The present study focused on detection of C. parvum oocysts in stool samples by the conventional microscopy (by wet mount 
technique, by Acid-Fast and Giemsa stains) compared to the detection of cryptosporidial copro-antigen by ELISA technique.

\section{Subjects, Material and Methods}

A total of ninety patients suffered from persistent diarrhea (minimum of 3 loose stools per day with duration of more than 2 weeks) in and outpatient clinics of Minia University Hospitals, after oral acceptance to be enrolled in this study. This study was done from March 2012 to February 2013.

A clean, plastic container was given to each person. One stool sample per subject was collected. All information, including personal identification, the stage of disease, and clinical symptoms were recorded. Fecal specimens were transported as soon as possible to the Parasitology Department, to be examined by different techniques for detection of parasitic infections within 0.5 to $1 \mathrm{hr}$ of collection. Samples were subjected to:-

Macroscopic examination identified color, odor, blood and mucus, round worms, pinworms, or tapeworm proglottids, as well as stool consistency.

Microscopy: a- Direct wet smear Saline wet mount to detect worm eggs or larvae, protozoan trophozoites, and cysts, and the presence of RBCs and WBCs, b- Iodine wet mount (Garcia et al, 1983) for glycogen and nuclei of protozoan cysts and c- Two stains; Modified Acid Fast (Casemore et al, 1985), and Giemsa stains (Garcia et al, 1983)

For ELISA: Rida-screen ${ }^{\circledR}$ Cryptosporidium kits (Cat No: C1201), (Clini-Lab, Cairo. Egypt). Cryptosporidium test, specific antibodies was used in a sandwich-type. Extinction was measured at $450 \mathrm{~nm}$ using a reference wavelength $600 \mathrm{~nm}$. Cut-off extinction for negative control +0.15 , sample was positive if extended more than $10 \%$ above calculated cut-off, sample was considered equivocal and was repeated if extended within $\pm 10 \%$ of the cut-off, and samples with extinctions more than $1 \%$ below the calculated cut-off was considered negative.

Statistical analysis: Package of SPSS version 16 for windows was used for data entry and analysis. Descriptive statistics were calculated. For qualitative data, $\chi^{2}$-test was used, and z-test was used for proportions, a significant $P$-value if less than 0.05 .

\section{Results}

The results are shown in tables (1 to 12 ).

Table 1: Parasites detected by saline and iodine examination:

\begin{tabular}{|l|c|c|}
\hline \multicolumn{1}{|c|}{ Parasites } & No. & Percentage \\
\hline Cryptosporidium parvum & 49 & $43.75 \%$ \\
\hline Giardia lamblia & 21 & $18.75 \%$ \\
\hline Blastocystis hominis & 10 & $8.9 \%$ \\
\hline Entamoeba histolytica/dispar & 12 & $10.7 \%$ \\
\hline Entamoeba coli & 10 & $8.9 \%$ \\
\hline Iodamoeba butchilii & 4 & $3.6 \%$ \\
\hline Hymenolepis nana & 3 & $2.7 \%$ \\
\hline Ascaris lumbricoides & 2 & $1.8 \%$ \\
\hline Isospora belli & 1 & $0.8 \%$ \\
\hline
\end{tabular}

Frequency distribution of qualitative data by number and $\%$

Table 2: Protozoan parasites detected by Modified Acid-Fast stain.

\begin{tabular}{|c|c|c|}
\hline Parasites & No. & Percentage \\
\hline Cryptosporidium spp. & 55 & $64 \%$ \\
\hline Cyclosora cayetanensis & 15 & $16.4 \%$ \\
\hline Giardia lamblia & 9 & $10.5 \%$ \\
\hline Entamoeba histolytica & 2 & $2.3 \%$ \\
\hline Entamoeba coli & 2 & $2.3 \%$ \\
\hline Isospora belli & 2 & $2.3 \%$ \\
\hline Chilomastix & 1 & $1.2 \%$ \\
\hline Total & 86 & $100 \%$ \\
\hline
\end{tabular}


Table 3: Protozoan parasites detected by Giemsa stain.

\begin{tabular}{|l|c|c|}
\hline Parasites & No. & Percentage \\
\hline Cryptosporidium parvum & 44 & $78.6 \%$ \\
\hline Blastocystis hominis & 6 & $10.7 \%$ \\
\hline Giardia lamblia & 4 & $7.1 \%$ \\
\hline Isospora belli & 2 & $3.6 \%$ \\
\hline Total & 56 & $100 \%$ \\
\hline
\end{tabular}

Table 4: Distribution of single and mixed protozoan parasites detected by wet mount

\begin{tabular}{|l|c|c|}
\hline Protozoan parasites & No. & Percentage \\
\hline Cryptosporidium only & 22 & $24.4 \%$ \\
\hline Cryptosporidium with other parasites & 27 & $30 \%$ \\
\hline Parasites other than Cryptosporidium & 16 & $17.8 \%$ \\
\hline No parasites & 25 & $27.8 \%$ \\
\hline Total & 90 & $100 \%$ \\
\hline
\end{tabular}

Table 5: Distribution of single and mixed protozoan parasites detected by modified acid-fast.

\begin{tabular}{|l|c|c|}
\hline Protozoan parasites & No & Percentage \\
\hline Cryptosporidium parvum only & 35 & $38.9 \%$ \\
\hline Cryptosporidium with other parasites & 20 & $22.2 \%$ \\
\hline Parasites other than Cryptosporidium & 14 & $15.6 \%$ \\
\hline No parasite & 21 & $23.3 \%$ \\
\hline Total & 90 & $100.0 \%$ \\
\hline
\end{tabular}

Table 6: Distribution of single and mixed protozoan parasites detected by Giemsa stain.

\begin{tabular}{|l|c|c|}
\hline Protozoan parasites & No. & Percentage \\
\hline Cryptosporidium parvum only & 38 & $42.2 \%$ \\
\hline Cryptosporidium with other parasites & 6 & $6.7 \%$ \\
\hline Parasites other than Cryptosporidium & 12 & $13.3 \%$ \\
\hline No parasite & 34 & $37.8 \%$ \\
\hline Total & 90 & $100.0 \%$ \\
\hline
\end{tabular}

Table 7: Relationship between age and Cryptosporidium parvum by acid fast stain

\begin{tabular}{|l|c|c|c|}
\hline \multirow{2}{*}{ Age group } & \multicolumn{2}{|c|}{ Positive Cryptosporidium infection } & \multirow{2}{*}{ P value } \\
\cline { 2 - 3 } & No. & Percentage & \multirow{2}{*}{0.7} \\
\hline Less than $1 \mathrm{y}$ to $15 \mathrm{y}$ & 29 & $52.7 \%$ & \\
\hline More than $15 \mathrm{y}$ & 26 & $47.3 \%$ & \\
\hline Total & 55 & $100 \%$ & \\
\hline
\end{tabular}

$\mathrm{Z}$ test of proportion to compare between two proportions

Table 8: Relation between age and Cryptosporidium parvum by Giemsa stain

\begin{tabular}{|c|c|c|c|}
\hline \multirow{2}{*}{ Age group } & \multicolumn{2}{|c|}{ Positive Cryptosporidium parvum } & \multirow{2}{*}{ P value } \\
\cline { 2 - 3 } & No. & Percentage & \\
\hline Less than $1 \mathrm{y}$ to $15 \mathrm{y}$ & 22 & $50 \%$ & \multirow{2}{*}{0.7} \\
\hline More than $15 \mathrm{y}$ & 22 & $50 \%$ & \\
\hline Total & 44 & $100 \%$ & \\
\hline
\end{tabular}

Table 9: Relation between sex and Cryptosporidium parvum by modified acid-fast.

\begin{tabular}{|l|c|c|c|c|c|c|}
\hline \multirow{2}{*}{ Sex } & C. parvum & $\begin{array}{c}\text { C. parvum \& } \\
\text { other parasites }\end{array}$ & $\begin{array}{c}\text { Parasites with- } \\
\text { out C. parvum }\end{array}$ & No parasites & Total & P value \\
\cline { 1 - 6 } Females & $13(37.1 \%)$ & $11(55 \%)$ & $8(57.1 \%)$ & $9(42.9 \%)$ & $41(45.6 \%)$ & \multirow{2}{*}{0.4} \\
\hline Males & $22(62.9 \%)$ & $9(45 \%)$ & $6(42.9 \%)$ & $12(57.1 \%)$ & $49(54.4 \%)$ & \\
\hline Total & $35(100 \%)$ & $20(100 \%)$ & $14(100 \%)$ & $21(100 \%)$ & $90(100 \%)$ & \\
\hline
\end{tabular}

Qui square test used to compare proportions 
Table 10: Relationship between sex and Cryptosporidium parvum by Giemsa stain.

\begin{tabular}{|l|l|l|l|l|l|l|}
\hline Sex & C. parvum & $\begin{array}{l}\text { C. parvum \& } \\
\text { other parasites }\end{array}$ & $\begin{array}{l}\text { Parasites with- } \\
\text { out C. parvum }\end{array}$ & No parasites & Total & P value \\
\cline { 1 - 6 } Females & $17(44.7 \%)$ & $3(50 \%)$ & $7(58.3 \%)$ & $14(41.2 \%)$ & $41(45.63 \%)$ & 0.7 \\
\cline { 1 - 5 } Males & $21(55.3 \%)$ & $3(50 \%)$ & $5(41.7 \%)$ & $20(58.8 \%)$ & $49(54.4 \%)$ & \\
\cline { 1 - 5 } Total & $38(100 \%)$ & $6(100 \%)$ & $12(100 \%)$ & $34(100 \%)$ & $90(100 \%)$ & \\
\hline
\end{tabular}

Table 11: Detection of C. parvum copro-antigen by ELISA:

\begin{tabular}{|l|c|c|}
\hline Cases & No & Percentage \\
\hline Positive cases & 80 & $88.9 \%$ \\
\hline Negative cases & 10 & $11.1 \%$ \\
\hline Total & 90 & $100 \%$ \\
\hline
\end{tabular}

Frequency distribution of qualitative data by number and $\%$

Table 12: Comparison between Modified Acid-Fast and ELISA

\begin{tabular}{|c|c|c|c|c|}
\hline \multirow{2}{*}{ Acid fast } & \multicolumn{2}{|c|}{ ELISA } & Total & \multirow{2}{*}{ P value } \\
\cline { 2 - 3 } & Positive & Negative & & \\
\hline Positive & $54(67.5 \%)$ & $1(10 \%)$ & $55(61.1 \%)$ & \multirow{2}{*}{0.0007} \\
\hline Negative & $26(32.5 \%)$ & $9(90 \%)$ & $35(38.9 \%)$ & \\
\hline Total & $80(100 \%)$ & $10(100 \%)$ & $90(100 \%)$ & \\
\hline
\end{tabular}

Qui square test used to compare proportions, ${ }^{*}$ significant test

Table 13: Comparison between Giemsa and ELISA

\begin{tabular}{|c|c|c|c|c|}
\hline \multirow{2}{*}{ Geimsa } & \multicolumn{2}{|c|}{ ELISA } & \multirow{2}{*}{ Total } & \multirow{2}{*}{ P value } \\
\cline { 2 - 3 } & Positive & Negative & & \multirow{2}{*}{0.01} \\
\hline Positive & $43(53.8 \%)$ & $1(10 \%)$ & $44(48.9 \%)$ & \\
\hline Negative & $37(46.3 \%)$ & $9(90 \%)$ & $46(51.1 \%)$ & \\
\hline Total & $80(100 \%)$ & $10(100 \%)$ & $90(100 \%)$ & \\
\hline
\end{tabular}

Table 14: Sensitivity and specificity for different stains and ELISA

\begin{tabular}{|l|c|}
\hline Sensitivity of ELISA & $90 \%$ \\
\hline Specificity of ELISA & $67.5 \%$ \\
\hline Positive predictive value of ELISA & $98.18 \%$ \\
\hline
\end{tabular}

\begin{tabular}{|l|l|l|}
\hline Acid fast stain & Value & $95 \%$ confidence interval \\
\hline Sensitivity & $67.5 \%$ & $0.561-0.776$ \\
\hline Specificity & $90 \%$ & $0.555-0.997$ \\
\hline Predictive value positive & $98.18 \%$ & $0.903-0.999$ \\
\hline Predictive value negative & $25.71 \%$ & $0.125-0.432$ \\
\hline Geimsa stain & Value & $95 \%$ confidence interval \\
\hline Sensitivity & $53.75 \%$ & $0.422-0.649$ \\
\hline Specificity & $90 \%$ & $0.555-0.997$ \\
\hline Predictive value positive & $97.73 \%$ & $0.879-0.999$ \\
\hline Predictive value negative & $19.57 \%$ & $0.093-0.339$ \\
\hline
\end{tabular}

Sensitivity $=$ true positive/ true positive + false negative, Specificity $=$ true negative/ true negative + false positive

\section{Discussion}

The present study confirmed that ELISA is superior to the light microscopic examination for the detection of C. parvum in stool samples. The sensitivity, specificity, and positive predictive value of the ELISA (in relation to the microscopic examination) were $90,67.5 \%$ and $98.18 \%$ respectively. In the present study $C$. parvum was the most protozoan parasite detected in the stool samples examined by both techniques. By using the wet mount technique, $C$. parvum can be detected in 49 stool samples $(54.4 \%)$ out of 90 stool samples. While, this number of positive samples for C. parvum increased to 55 samples $(61 \%)$ out of 90 stool samples by using the Modified Acid-Fast stain. One the other hand, the number of $C$. parvum de- 
creased to $44(48.8 \%)$ out of 90 stool samples by using Giemsa stain.

These results indicated that Modified Acid-Fast stain is the most effective stain in the detection of $C$. parvum oocysts in fecal samples. These results agreed with those of Kamal et al. (2008) who stated that Modified Acid-Fast stain was more effective in the detection of $C$. parvum oocysts. Also, the use of ELISA technique results in increased the number of $C$. parvum positive in $80(88.9 \%)$ out of 90 samples.

The present study showed that Modified Acid-Fast stain diagnosed 55 cases $(61.1 \%)$ and Giemsa stain can diagnose only 44 cases $(48.9 \%)$ with $\mathrm{P}=0.1$. This indicated that both stains detected C. parvum oocysts. Although the number of positive cases detected by Modified Acid-Fast stain was more than that detected by Giemsa stain, but without significant $(\mathrm{P}=0.1)$. The present results agreed with Garcia et al. (1093) who reported that both Giemsa and modified AcidFast stains were the most effective methods for C. parvum identification in examined stool samples. Kamal et al. (2008) reported that Modified Acid-Fast stain is more effective in the detection of Cryptosporidium spp. On the other hand, the results obtained by Fagbenro-Beyioku et al. (2006) were partially compatible with the present results as Modified Acid-Fast stain was more effective in diagnosing of C. parvum oocysts ( $35.7 \%$ ) than Giemsa stain (3\%). They concluded that wet mount technique was ineffective for diagnosis of cryptosporidiosis.

In the present study, C. parvum oocysts were detected either alone in 35 cases $(38.9 \%)$ or mixed with other parasites in 20 cases $(22.2 \%)$ by using Modified Acid-Fast stain, while Giemsa stain detected Cryptosporidium alone in 38 cases $(42.2 \%)$ or mixed with other parasites in 6 cases $(6.7 \%)$. This agreed with the detection of mixed infections of $21.7 \%(5 / 23)$ in positive patients (Abd El Kader et al, 2012). No doubt, cryptosporidiosis is a common pathogen present in cases with mixed infections. This agreed with Philips et al. (1992) in London, but in Jakarta and Ethiopia mixed infection occurred in $7 \%$ and $2.6 \%$ respectively (Kurniawan et al, 2009; Wegayehu et al, 2011).

The high percentage of mixed parasites detected by modified acid-fast stain $(22.2 \%)$ (C. parvum with other parasites) may be explained by the fact that an established parasite paves the way for flourishing of other parasites (MacKenzie et al, 1994).

In this study showed no age predilection for cryptosporidial infection as $52.7 \%$ of cases were below 15 years and $47.3 \%$ were above 15 years old. The present results come in agree with the results revealed by a study done in western Venezuela which reported that there is no age predilection for cryptosporidiosis i (Chaci'n-Bonilla and Sa'nchezcha'vez, 2000). In the United States from 2006 to 2008 the majority of Cryptosporidi$u m$ were from children aged 1-9 years and adults aged 25-39 years (Yoder et al, 2010).

In Iraq higher infection appeared in age below one year (Rahi et al, 2013). Another study on acute diarrheic patients in NorthEastern India reported that the most commonly infected age group was $16-45$ years. and no significant difference in the occurrence of cryptosporidiosis was observed in children under the age of 5 years (Nath et al, 1999). In Kano state, Nigeria highest prevalence rate of $C$. parvum was in patients aged 46 to 55 years old (Kumurya and Gwarzo, 2013). In Plateau State, North-Central Nigeria cryptosporidiosis was the highest $11.0 \%$ $(33 / 300)$ in ages $0-10$ years and lowest $1.7 \%$ (5/300) in ages; $31-40$ years (Pam et al, 2013).

In the present study, no significant difference was recorded between males and females as $63.3 \%$ of the cryptosporidiosis cases were males while $58.5 \%$ were females. This might be due to environmental conditions as over crowdedness, water sources, improper sewage disposal and resistance of the oocyst to the routinely used disinfectant watersheds (Philip et al, 2008). These results are in agreement with another study done in 
Cairo, Egypt which reported that $55.6 \%$ of infected cases of cryptosporidiosis cases were males and $44.4 \%$ were females (ElHelaly et al, 2012). Also, the results agreed with Abd El Kader et al. (2012) in Cairo, Egypt. The results are also more or less similar to a study in Iraq which showed that the prevalence of Cryptosporidium infection was $33.74 \%$ in the males and $33.93 \%$ in females (Rahi et al, 2013). A study of cryptospordiosis in Sulaimani pediatric teaching hospital recorded that there was no significant difference between males and females (Ali and Ali, 2013). Gatei et al. (2006) found that infection rates did not vary with gender distribution. Another recent study done in Nigeria reported that no significant difference was present between males and females (Pam et al, 2013). Mumtaz et al. (2010) observed high prevalence rate of cryptosporidiosis in males. Moreover, the study carried in Iran found that there was a statistically significant relationship between Cryptosporidium and sexes. They recorded that boys are more susceptible to cryptosporidiosis than girls (Khalili and Mardani, 2009). The present results revealed that ELISA technique increased the detected number of $C$. parvum to $80(88.9 \%)$ out of 90 stool samples when compared to positive number detected by Modified Acid-Fast stain $(55$ or $61.1 \%)$ or by Giemsa stain (44 or $48.9 \%)$ with statistical significant $(\mathrm{p}=$ less than 0.05 ). The positive predictive value of Acid-Fast stain was $98.18 \%$ while that of Giemsa stain and ELISA were $97.73 \%$ \& $98.18 \%$ respectively. The present results also revealed that modified acid-fast stain proved to be good negative test but not good positive one, but better than Geimsa in detecting the parasite with sensitivity of $67.5 \%$. Geimsa stain proved to be good negative test but not good positive one with sensitivity of $53.75 \%$. ELISA proved to good positive and good negative test with a sensitivity of $90 \%$. These results agreed with those of AbdelMessih et al. (2005) among children and those of Nautiyal et al, (2013) among adults.
The copro-antigen detected 97 (4.9\%) of 2000 Turkish children by ELISA, and cryptosporidial oocysts were in 39 children $(1.95 \%)$ by light microscopy (Yilmaz et al, 2008). In Brazil a study compared Modified Acid-Fast stain with ELISA reported that the sensitivity of ELISA was $100 \%$, with a specificity of $96 \%$; positive and negative predictive values were $89 \%$ and $100 \%$, respectively (Marques et al, 2005). In India the sensitivity and specificity for ELISA for detection of cryptosporidial copro-antigin in stool samples were $90.9 \%$ and $98.7 \%$ respectively (Sarkar et al, 2013). In Iraq a study showed $100 \%$ positive by microscopic examination and $72.5 \%$ by ELISA (Rahi et al, 2013). Although ELISA test is expensive and has the possibility of false positive results (Vohra et al, 2012), it is simple, rapid, reliable, and specific test and may be useful for large-scale epidemiological studies of cryptosporidiosis, and also confirmed (Jayalakshmi et al, 2008).

In Egypt, cryptosporidiosis is one of the serious zoonotic parasites (Helmy et al, 2014). The first C. parvum case was 18 month old child (Azab et al, 1985), in outpatient clinic of Abu El Riche Children's Hospital with acute diarrhea. Since then, so many Egyptian authors too much to mention described zoonotic human cryptosporidiosis. Youssef et al. (2008) reviewed more than 61 Egyptian publications on cryptosporidiosis and stated that $C$. parvum diarrhea was but one of the many causes of diarrhea among Egyptians, but efforts to control this disease should also serve well to mitigate a number of infectious causes of diarrhea especially among children. Massoud et al. (2008) stated that zoonotic cryptosporidiosis is one of the public health and veterinary importance protozoa not only in Egypt, but also worldwide at least in the developing countries. They treated patients in Mansoura University Hospitals by a combination of Mirazid ${ }^{\circledR}$ and Paromomycin ${ }^{\circledR}$. In Ismailia Governorate, Shoukry et al. (2009) reported infection rate of $88.2 \%$ among cryptosporidiosis children 
compared to those $11.8 \%$ that not in contact with animals. Water samples examined showed $0.0 \%$ in bottled water up to $9.33 \%$ in water tank. C. parvum in farm animals was $20.9 \%$ in sheep, $22.5 \%$ in buffaloes, $23.7 \%$ in cows and $25.9 \%$ in goats.

\section{Conclusion}

Cryptosporidiosis causes diarrheal disease with 10 Cryptosporidium species infecting nearly all mammals worldwide. C. parvum, the most important species, was an endemic zoonotic coccidian highly prevalent in many of the developing countries, and responsible for up to $20 \%$ of the childhood diarrhea. The common mode of transmission included waterborne, animal contact, food-borne, or man to man contact with oocysts. ELISA is simple, rapid, reliable, sensitive and specific for routine diagnosis and may be useful for large-scale epidemiological studies of Cryptosporidiosis. In the present study, the sensitivity, specificity, and positive predictive value of the ELISA in relation to microscopy were $90,67.5 \%$, and $98.18 \%$ respectively.

\section{References}

Abd El Kader, NM, Blanco, MA, Ali, TM, Abd El Ghaffar, AR, Osman, A, et al, 2012: Detection of Cryptosporidium parvum and Cryptosporidium hominis in human patients in Cairo, Egypt. Parasitol. Res, 110:161-6

Abdel-Messih, IA, Wierzba, TF, AbuElyazeed, R, Ibrahim, AF, Ahmed, S, et al, 2005: Diarrhea associated with Cryptosporidium parvum among young children of Nile River Delta in Egypt. J. Trop. Pediatr., 51:154-9.

Ali, FM, Ali, SA, 2013: Cryptosporidiosis in Sulaimani pediatric teaching hospital and comparison of different diagnostic methods for its detection. Euro Sci. J. 9:.36-9.

Azab, ME, Khalil, HM, Khalifa, AS, Makhlouf, SA, Habib, SM, 1985: Cryptosporidiosis as a possible cause of diarrhea in children. Egypt. J. Paediat. 2: 547-353.

Casemore, DP, Sands, RL, Curry, A, 1985: Cryptosporidium species a "new" human pathogen. J. Clin. Pathol, 38:1321-36

Casemore, DP, Sands, RL, Curry, A, 1985: Cryptosporidium species a "new" human pathogen. J. Clin. Pathol.38:1321-36.
Chaci'n-Bonilla, L， Sa'Nchez-cha'vez，Y， 2000: Intestinal parasitic infections, with a special emphasis on cryptosporidiosis, in Amerindians from western Venezuela .Am. J. Trop. Med. Hyg., 62:347-52

Chen, XM, Keitely, JS, Paya, CV, Larusso, N F, 2002: Cryptosporidiosis. N. Engl. J. Med. 346, 1723-31.

Current, WL, Garcia, LS, 1991: Cryptosporidiosis. Clin. Microbiol. Rev.4:325-58.

El-Helaly, NS, Aly, MM, Attia, SS, 2012: Detection of Cryptosporidium Infection among Children with Diarrhea. J. Sci. J. 5:68-76.

Fagbenro-Beyioku, A, Oyibo, W, Onuoha, E, Ukaegbu, C, Ojuromi, O, 2006: Evaluation of microscopic staining techniques for the diagnosis of opportunistic protozoan infections in a developing country. Internet J. Trop. Med. 3: 2-5. Fayer, R, Morgan, U, Upton, SJ, 2000: Epidemiology of Cryptosporidium: transmission, detection, and identification. Int. J. Parisitol. 30: 1305-22.

Garcia, LS, Bruckner, DA, Brewer, TC, Shimizu, RY, 1983: Techniques for the recovery and identification of Cryptosporidium oocysts from stool specimens. J. Clin. Microbiol. 18:185-90.

Gatei, W, Wamae, CN, Mbae, C, Waruru, A, Mulinge, E, et al, 2006: Cryptosporidiosis: prevalence, genotype analysis, and symptoms associated with infections in children in Kenya. Am. J. Trop. Med. Hyg. 75:78-82.

Helmy, YA, VON Samson-Himmelstjerna, G, Nöckler, K, Zessin, KH, 2014: Frequencies and spatial distributions of Cryptosporidium in livestock animals and children in the Ismailia province of Egypt. Epidemiol. Infect. 2014 Aug 1:111. [Epub ahead of print]

Huang, DB, Chappell, C, Okhuysen, PC, 2004: Cryptosporidiosis in children. Semin Pediatr. Infect. Dis. 15:253-9.

Jayalakshmi, J, Appalaraju, B, Mahadevan, K, 2008: Evaluation of an enzyme-linked immunoassay for the detection of Cryptosporidium antigen in fecal specimens of HIV/AIDS patients. Indian J. Pathol. Microbiol. 51:137-8.

Kamal, KA, El-Dib, NA, Hassanin, FS. 2008: Evaluation of immunoflourescent anti body (IFA) kit for the detection of $C$. parvumoocysts and Giardia latmblia cysts in stool specimens. PUJ. 1, 2:145-7.

Khalili, B, Mardani, M, 2009: Frequency of Cryptosporidium and risk factors related to cryp- 
tosporidiosis in under 5-year old hospitalized children due to diarrhea. Iranian J. Clin. Infect. Dis. 4:151-5.

Kumurya, AS, Gwarzo, MY, 2013: Cryptosporidiosis in HIV infected patients with diarrhoea in Kano state, North-western Nigeria. J. AIDS/HIV Res. 5:301-5.

Kurniawana, A, Karyadib, T, Dwintasaria, SW, Sari, IP, Yunihastutib, E, et al, 2009: Intestinal parasitic infections in HIV/AIDS patients presenting with diarrhea in Jakarta, Indonesia. J. Roy. Soc. Trop. Med. Hyg, 103: 892-8.

Mac Kenzie, WR, Hoxie, NJ, Proctor, ME, Gradus, MS. Blair, KA, et al, 1994: A massive outbreak in Milwaukee of Cryptosporidium infection transmitted through the public water supply. N. Engl. J. Med. 331:161-7.

Marques, FR, Cardoso, LV, Cavasini, CE, Almeida, MC, Bassi, NA, et al, 2005: Performance of an immunoenzymatic assay for Cryptosporidium diagnosis of fecal samples. Braz. J. Infect. Dis. 9:3-5.

Massoud, AM, Hafez, AO, Abdel-Gawad, A G, El-Shazly, AM, Morsy, TA, 2008: Mirazid alone or combined with Paromomycin in treating cryptosporidiosis parvum in immunocom-petent hospitalized patients. J. Egypt. Soc. Parasitol. 38, 2:399-418.

Mumtaz, S, Ahmed, J, Ali, L, 2010: Frequency of Cryptosporidium infection in children under five years of age having diarrhea in North West of Pakistan. Afr. J. Biotech. 9:1230-35.

Nath, G, Choudhury, A, Shukla, BN, Singh, TB, Reddy, DC, 1999: Significance of Cryptosporidium in acute diarrhea in North-Eastern India. J. Med. Microbiol. 48:523-6.

Nautiyal, S, Pinto, MJW, Rodrigues, S, 2013: A comparative study of various diagnostic techniques for Cryptosporidiosis. J. Pharm. Biol. Sci. 6:1-6.

Nime, FA, Burek, JD, Page, DL, Holscher, MA, Yardley, JH, 1976: Acute enterocolitis 2in a human being infected with the protozoan Cryptosporidium. Gastroenterol. 70:592-8.

Pam, VA, Dakul, DA, Karshima, NS, Igeh, CP, 2013: Occurrence of Cryptosporidium species and other zoonotic parasites among humans in Jos, Plateau State, North-Central Nigeria. Asian J. Biomed. Pharm. Sci. 3:20-4.

Philip, DA, Rawlins, SC, Baboolal, S, Gosein, R, Goddard, C, Legall, et al, 2008: Relative importance of the various environmental sources of Cryptosporidium oocysts in three watersheds. J. Water Hlth. 6, 23-34.

Phillips, AD, Thomas, AG, Walker-Smith, JA, 1992: Cryptosporidium, chronic diarrhea and the proximal small intestinal mucosa. Gut 33:105761

Priest JW, Bern C, Xiaol, Roberts JM, et al, 2006: Longitudinal analysis of Cryptosporidium species-specific IgG antibody responses in Peruvian children. Clin. Vac. Immunol. 13, 1:123-31. Rahi, AA, Ali, MA, Al-Charrakh, AH, 2013: Prevalence of Cryptosporidium Parvum among Children in Iraq. Amer. J. Life Sci., 1:256-60.

Sarkar, R, Ajjampur, SS, Prabakaran, AD, Geetha, JC, Sowmyanarayanan, TV, et al, 2013: Cryptosporidiosis among children in an endemic semiurban community in southern India: does a protected drinking water source decrease infection? Clin. Infect. Dis. 57, 3:398406.

Vohra, P, Sharma, M, Chaudhary, U, 2012: A comprehensive review of diagnostic techniques for detection of cryptosporidium parvum in stool samples. IOSR J. Pharma, 2:15-26.

Weber, R, Bryan, RT, Bishop, HS, Wahlquist, SP, Sullivan, JJ, et al, 1991: Threshold of detection of Cryptosporidium oocysts in human stool specimens: evidence for low sensitivity of current diagnostic methods. J Clin Microbiol, 29, 1323-7.

Wegayehu, T, Adamu, H, Petros, B, 2011: Prevalence of Giardia duodenalis and Cryptosporidium species infections among children and cattle in North Shewa Zone, Ethiopia. BMC Infect. Dis. 13:419-24.

Xiao, L, Fayer, R, Ryan, U, Upton, SJ, 2004: Cryptosporidium taxonomy: recent advances and implications for public health. Clin. Microbiol.Rev. 17:72-97.

Yilmaz, H, Tas-Cengiz, Z, Cicek, M, 2008: Investigation of cryptosporidiosis by enzymelinked immunosorbent assay and microscopy in children with diarrhea. Saudi Med. J. 29, 526-9.

Yoder, JS, Harral, C, Beach, MJ, 2010: Cryptosporidiosis surveillance-United States, 20062008. MMWR Surveill. Summ. 59:1-14.

Youssef, FG, Adib, I, Riddle, MS, Schlett, CD, 2008: A review of cryptosporidiosis in Egypt. J. Egypt. Soc. Parasitol. 38, 1:9-28 